\title{
BMJ Open Loneliness and mental well-being in the Polish population during the COVID-19 pandemic: a cross-sectional study
}

\author{
Ewa Kobos (D) ,,2 Barbara Knoff, ${ }^{2}$ Beata Dziedzic, ${ }^{2}$ Rafał Maciąg, ${ }^{2}$ Anna Idzik ${ }^{2}$
}

To cite: Kobos E, Knoff B, Dziedzic B, et al. Loneliness and mental well-being in the Polish population during the COVID-19 pandemic: a crosssectional study. BMJ Open 2022;12:e056368. doi:10.1136/ bmjopen-2021-056368

- Prepublication history and additional supplemental material for this paper are available online. To view these files, please visit the journal online (http://dx.doi.org/10.1136/ bmjopen-2021-056368)

Received 12 August 2021 Accepted 10 January 2022

Check for updates

(C) Author(s) (or their employer(s)) 2022. Re-use permitted under CC BY-NC. No commercial re-use. See rights and permissions. Published by BMJ.

${ }^{1}$ Department of Development of Nursing, Social and Medical Sciences, Faculty of Health Sciences, Medical University of Warsaw, Warsaw, Poland

${ }^{2}$ Medical University of Warsaw, Warsaw, Poland

Correspondence to

Dr Ewa Kobos;

ekobos@wum.edu.pl

\section{ABSTRACT}

Objective There is a growing concern that the restrictions imposed due to the COVID-19 pandemic could lead to increased loneliness and mental disorders, which are considered a major public health problem. The aim of the study was to assess loneliness, anxiety, depression and irritability in the Polish population during the COVID-19 pandemic.

Design A cross-sectional study. The study participants completed an online questionnaire using the computerassisted web interview technique. Data were collected using Revised UCLA Loneliness Scale and Hospital Anxiety and Depression Scale.

Setting Poland.

Participants This study was conducted between 6 October and 12 0ctober 2020, in a representative sample of 890 Polish residents.

Primary outcome measures Self-reported loneliness; sociodemographic and COVID-19 pandemic factors associated with loneliness, anxiety, depression and irritability.

Results The analyses showed a moderately high degree of loneliness in $22 \%$, symptoms of anxiety in $27 \%$, depression in $14 \%$ and irritability in $33 \%$ of the respondents. The increasing severity of anxiety, depression and irritation in the study group was accompanied by higher loneliness. Generally, younger people, both tested positive for SARS-CoV-2 and those who experienced home quarantine, scored higher in both scales.

Conclusions It is necessary to identify those most vulnerable to loneliness, anxiety and depression during a crisis to assess health needs and proactively allocate resources during and after the pandemic. Loneliness, anxiety, depression and irritability are important factors to consider in a population of younger, disadvantaged people, who tested positive for SARS-CoV-2, people who were quarantined at home, and people who believe that their physical and mental health is worse than in the prepandemic period. It is important to cater for the mental health of individuals during the COVID-19 pandemic and to promote psychological interventions to improve mental well-being in potentially vulnerable social groups.

\section{BACKGROUND}

In March 2020, governments of many countries began to implement relatively harsh pandemic-related restrictions and most citizens were confined to their homes to limit
Strengths and limitations of this study

The study was conducted in a representative sample of Polish residents.

- The current data were collected through online surveys, which may have excluded potential respondents who lack internet access or are not knowledgeable about modern technologies.

- The cross-sectional survey design precluded conclusions about causality.

the spread of the SARS-CoV-2 virus. The first case of SARS-CoV-2 infection in Poland was confirmed on 4 March 2020. ${ }^{12}$ Full lockdown was implemented on $25 \mathrm{March}$, with illegal gatherings of more than two people and restrictions on leaving home, including a recommendation to work remotely. ${ }^{3}$ This meant that most of the employees started working from home and that people stayed at home most of the time. The restrictions involved the protection of mouth and nose in public places, social distancing, cancellation of public events, limiting the number of customers in stores, closing of shopping centres, ban on international travel and closed airports. In the spring of 2020, the COVID-19 epidemic was suppressed by implementing massive restrictions on social contacts. ${ }^{4}$ As of 23 December 2021, the global number of reported COVID-19 cases reached 276 436 619, including 5374744 deaths, and it continues to grow. ${ }^{5}$ In Poland, from 3 January 2020 to 23 December 2021, there were 4017 420 confirmed cases of COVID-19 with 93445 deaths. ${ }^{5}$ In the period from 6 to 12 October 2020, when this study was conducted, a total of 2236-5300 daily new cases and from 32 to 75 deaths per day were recorded in Poland, and the total number of cases was 104316 on 6 October 2020 and 130210 on 12 October $2020 .^{5}$

Loneliness can be defined as a distressing feeling resulting from a dissatisfaction with the quality and quantity of one's social 
relationships. ${ }^{6}$ Loneliness has long been recognised as a risk factor for poor mental health; however, since the outbreak of the COVID-19 pandemic, it has emerged as a critical public health issue ${ }^{7-9}$ Loneliness is a strong risk factor for many diseases, for example, cardiovascular diseases and is associated with an increased risk of mortality. ${ }^{70-13}$ Chronic loneliness is characterised by deficits in attention, affect, cognition, and behaviour that affect genetic, neural, and hormonal mechanisms, and thus contribute to higher morbidity and mortality rates. ${ }^{14}$ Apart from its detrimental influence on physical health, COVID-19 also affects people's mental well-being, which may lead to numerous psychological problems. ${ }^{15-20}$ People are more likely to experience different levels of fear of illness or death, a sense of helplessness and stigma after being infected with SARS-CoV-2. ${ }^{21}$ Loneliness may become an alarming global problem due to the pandemic-related social and physical distancing. Current research points to two important factors contributing to poor emotional well-being in lockdown: an increase in loneliness and more screen time. ${ }^{22} \mathrm{~A}$ study by Groarke $e t$ al demonstrated the incidence rate of loneliness among UK citizens to be $27 \%$ in lockdown, with one in four respondents admitting to feeling lonely 'in the previous 2 weeks'. ${ }^{23}$ Increased loneliness during the pandemic was found in adult Norwegians, as compared with the pre-pandemic period. ${ }^{24}$ In Canada, $8.4 \%$ of respondents reported feeling lonely for at least 5 days in the week prior to the study. ${ }^{25}$ There are reports that show a positive correlation between the pandemic-related necessity to stay at home and the perceived level of loneliness. Tull et al found that although staying at home was associated with increased loneliness, the perceived impact of COVID-19 alone was negatively correlated with loneliness. ${ }^{17}$ Those suffering from COVID-19 received even greater support from their immediate environment. These findings correspond with suggestions that widespread shared COVID-19 experiences can increase social closeness and cohesion. ${ }^{26}$

As far as mental health, loneliness and social isolation are concerned, not only do they strongly correlate with depression, but they may also increase the risk of future depressive episodes. ${ }^{27-30}$ The incidence rates of anxiety and depressive disorders in a systematic review of studies on stress, anxiety and depression in the general population during the COVID-19 pandemic were $31.9 \%$ and $33.7 \%$, respectively. ${ }^{16}$ The highest prevalence of anxiety $(32.9 \%)$ and depression $(35.3 \%)$ was found in Asia, and the highest prevalence of stress was observed in Europe $(31.9 \%) .{ }^{16}$ The general data on anxiety, depression and psychological stress during the pandemic show that the mean prevalence rates of anxiety and depression are $38.12 \%$ and $34.31 \%$, respectively. ${ }^{31}$ Luo et al showed a combined incidence of anxiety and depressive disorders in $32 \%$ and $27 \%$ of the general population, respectively. ${ }^{32}$ Castaldelli-Maia et al estimated the worldwide pandemicrelated prevalence of both depression and anxiety at $24.0 \%$ and $21.3 \%$, respectively. ${ }^{33}$
Latest research seems to confirm that people in isolation or quarantine are more likely to show significant levels of anxiety, anger, confusion and stress. ${ }^{34}$ Research data from the COVID-19 pandemic demonstrate that people affected by quarantine present with stress, emotional anxiety, depression, mood swings, aggression, anger, attention deficits, hyperactivity, insomnia and post-traumatic stress. ${ }^{35-43}$ Contrary to the reviews of crosssectional studies, a meta-analysis of longitudinal studies and natural experiments assessing the link between the COVID-19 lockdown and mental health indicates that the initial impact of the lockdown on mental health is relatively small. Research findings suggest high mental toughness of people in response to the necessity to stay at home, lockouts and restrictions that were likewise implemented nationally or regionally around the world in response to the COVID-19 pandemic. ${ }^{44}$ Since these findings concern the first lockdowns during the COVID-19 pandemic, which were introduced between January and June 2020, the impact of repeated or prolonged lockdown on mental well-being requires further studies. The exact impact of the COVID-19 pandemic on mental health may vary across social groups, as well as across contexts and countries.

This study, which is representative of the Polish population, is one of the few studies conducted in Poland that focused on the impact of the COVID-19 pandemic on the mental health of Polish citizens. A study by Szczesniak $e t$ al demonstrated that apart from preventing the spread of COVID-19, the requirements on the use of face masks may have contributed to the perceived level of self-protection and promotion of social solidarity, which, in turn, may have improved the overall mental health. ${ }^{45}$ However, it should be noted that these data were collected from 16 March to 26 April 2020, that is, in the first week of the regulations on the use of face masks in Poland. A study by Hamer and Baran on the impact of the pandemic on the mental well-being of Polish population showed increased loneliness and greater distress in the age group of 18-24 years old. The study was repeated four times between March and December 2020. ${ }^{46}$ The research conducted in Poland in the group of students (20-26 April 2020, $\mathrm{n}=2170$; mean age $22.1 \pm 2.2$ years) showed moderate to very severe depression and anxiety in $43.4 \%$ and $27.3 \%$ of the respondents, respectively. ${ }^{47}$ A mean Revised UCLA Loneliness Scale (R-UCLA) score of 42.041 out of a maximum of 80 was obtained in a study conducted 1.5 weeks after the introduction of home isolation in Poland (3 April 2020), in a group of 471 respondents (students accounted for $61.6 \%$ of the group; mean age $25.5 \pm 2$ years).$^{48}$ It was shown that the criterion for minor mental disorders ( $\geq 24$ points) in the General Health Questionnaire (GHQ) scale was met by $59.2 \%$ of respondents $(\mathrm{n}=2155)$ at the peak of the second wave of the pandemic in Poland (November 2021). ${ }^{49}$

Early detection of mental disorders allows for more effective intervention strategies. Global health crises, for example, such as the COVID-19 pandemic, affect not 
only healthcare workers, but also the general population, and result in undesirable psychological changes induced by fear, anxiety, depression or insecurity. ${ }^{50}$ The Lancet published a consensus statement calling for research on the impact of the COVID-19 pandemic on mental health in the whole population as well as in vulnerable groups. ${ }^{51}$ It is therefore necessary to assess and supervise the mental health of various population groups during crises such as a pandemic. The aim of the study was to assess loneliness, anxiety, depression and irritability in the Polish population during the COVID-19 pandemic.

\section{METHODS}

\section{Patient and public involvement}

No patient involved.

\section{Participants and data collection}

The study was conducted from 6 October to 12 October 2020 in a representative sample of Polish residents $(\mathrm{N}=890)$, which was selected using the random-quota method. A two-stage random sampling was performed, in which places of residents were randomly selected first, and then a quota sample was made. The quotas were selected for gender, age, education, size of the place of residence and province. The above-mentioned layers were used to select study participants. Fulfilment of the general population representativeness criteria by the study participants was the study criterion. Only those with access to the internet and ability to use a computer or other devices that enable answering questions via an internet panel were included in the study. After sending an inquiry regarding confirmation of consent to participate in the study, $40 \%$ of respondents refused to participate in the study. The size of the study group was supplemented with the assumed amount (890 participants in relation to the National Census of the Polish Population) in accordance with the above-mentioned amounts.

The respondents completed an online questionnaire using the computer-assisted web interview technique. The study was conducted by Kantar, which is one of the global research companies, using a website dedicated to this study. In compliance with the International Chamber of Commerce (ICC) /European Society for Opinion and Marketing Research (ESOMAR) International Code, personal data protection requirements and other applicable laws and principles set out in the national code of good research practice, the recruitment of study participants was conducted using the database of the research company responsible for conducting our study, in compliance with all the representativeness of the study group. ${ }^{52}$ Each of the potential respondents was asked for consent to conduct the study. It was only after obtaining the consent that the respondent received a link to the questionnaire. The answers provided by the respondents were stored in the Information Technology system of the company conducting the study. This was followed by database creation.

\section{Measurement}

\section{Sociodemographic and COVID-19-related data}

The questionnaire used to collect sociodemographic data of the study participants enquired about age, sex, place of residence, education, marital status, professional status, type of accommodation, number of people per household, income level, financial situation, and type of work before and during the pandemic. Questionnaire data related to the pandemic period included: a diagnostic test for SARS-CoV-2; home quarantine during the coronavirus pandemic and currently; home/hospital isolation; having family members/friends who were tested positive for SARS-CoV-2; and those in home quarantine or home/ hospital isolation.

\section{Revised UCLA Loneliness Scale}

We used the Polish adaptation of the R-UCLA Loneliness Scale to assess loneliness. ${ }^{53}$ The scales are characterised by good reliability: total score $\alpha=0.92$, intimate others $\alpha=0.90$, social others $\alpha=0.83$, belonging and affiliation $\alpha=0.80$. The original scale, that is, UCLA Loneliness Scale, was first designed by Russell, Peplau and Cutron

${ }^{54}$ It comprises 20 items; the respondents indicate how often each statement is true for them on a 4-point scale ( $1=\mathrm{I}$ never feel this way, $4=\mathrm{I}$ often feel this way). The maximum score is 80 . The total score is the sum of scores from three subscales: belonging and affiliation, intimate others and social others. ${ }^{55}$ Based on Perry's classification, the following degrees of loneliness were set for the entire scale: 65-80, a high degree; 50-64, a moderately high degree; 35-49, a moderate degree; 20-34, a low degree of loneliness. ${ }^{56}$ In this study, the reliability coefficient was $\alpha=0.91$ for the entire questionnaire, $\alpha=0.90$ for intimate others (subscale); $\alpha=0.86$ for social others (subscale), and $\alpha=0.69$ for belonging and affiliation (subscale).

\section{Hospital Anxiety and Depression Scale}

The Polish version of Hospital Anxiety and Depression Scale (HADS-M) comprises 16 questions, with 2 additional questions on irritability. ${ }^{57}$ It is a modified version of HADS (the Hospital Anxiety and Depression Scale) by Zigmond and Snaith. ${ }^{58}$ The HADS-M includes three independent subscales: depression, anxiety and irritability; consisting of a total of 16 questions (each can be scored 0-3): depression subscale (seven questions) with the maximum score of 21; anxiety subscale (seven questions) with the maximum score of 21; irritability subscale (two questions) with the maximum score of 6 . A higher score in the subscales indicates a higher level of the feature assessed. Based on the original scale, the following interpretation of the anxiety and depression subscales was used to analyse the prevalence of symptoms: no disorders $(0-7)$, borderline states $(8-10)$ and disorders $(>10)$. The interpretation of the irritability subscale was as follows: 0-2: no disorders, 3: borderline states, 4-6: disorders. The maximum score was 48 . For the consolidated evaluation, individual states can be defined as: 0-16, no disorders; 17-22, border states; 23-48, disorders. 
Table 1 Subjects' R-UCLA scores $(n=890)$

\begin{tabular}{|c|c|c|c|c|c|c|}
\hline \multicolumn{3}{|l|}{ R-UCLA Scale } & \multicolumn{4}{|c|}{ Degrees of loneliness (\%) } \\
\hline Subscales & $\mathbf{M}$ & SD & Low & Moderate & Moderately high & High \\
\hline Intimate others & 22.40 & 6.77 & 36 & 40 & 22 & 2 \\
\hline Belonging and affiliation & 9.52 & 2.95 & & & & \\
\hline Total score & 40.40 & 10.79 & & & & \\
\hline
\end{tabular}

M, mean difference; R-UCLA, Revised UCLA Loneliness Scale.

In most analyses, the two subscales of depression and irritability are combined to present the results more clearly. In this study, the total reliability was $\alpha=0.92 ; \alpha=0.87$ for the anxiety, $\alpha=0.84$ for the depression and $\alpha=0.88$ for the irritability subscale.

\section{Data analysis}

The Shapiro-Wilk test was used to verify the normality of distributions and the Levene test was used to assess the homogeneity of variance. The following tests were used to assess the differences between the groups: for more than two compared groups, one-way analysis of variance or (when the assumption of equal variance was not met) the Welch's test along with the Tukey's post-hoc tests; under special circumstances (small and very diverse numbers between groups), the Kruskal-Wallis test was used along with the Dunn post-hoc test; for two compared groups, Student's t-test for independent variables or the Cochran-Cox test (when the assumption of equal variance was not met). Correlation analyses were performed using the Pearson linear correlation coefficient or the Spearman correlation coefficient (r). Statistica V.10.0 was used for calculations. The results of the analyses were considered statistically significant at $\mathrm{p} \leq 0.05$.

\section{RESULTS}

\section{Characteristics of the study group}

The study included $49.2 \%$ men and $50.8 \%$ women. The mean age of respondents was $44.3 \pm 16.10$ years. Secondary education was declared by $51.5 \%$ of respondents, there were $38 \%$ of rural respondents, $52 \%$ of professionally active respondents and $56.4 \%$ of married respondents. A total of $51.5 \%$ of the respondents lived in a single-family house, $59.4 \%$ of the respondents lived with their family and $10.3 \%$ lived alone (see online supplemental file 1 ).

\section{Loneliness}

Table 1 summarises data on the levels of loneliness in the study group. Overall, the mean R-UCLA score was $40.40 \pm 10.79$. Moderately high and high degree of loneliness were found in $22 \%$ and $2 \%$ of respondents, respectively.

\section{Anxiety, depression and irritability}

Table 2 shows the data obtained in the HADS-M. The mean score obtained by the respondents was $15 \pm 9.56$; disorders in anxiety and depression subscales were found in $27 \%$ and $14 \%$ of respondents, respectively.

\section{Anxiety, depression, irritability and the feeling of loneliness}

Table 3 shows positive statistically significant correlations between HADS-M and R-UCLA scores. The data show that the rate of loneliness increased with an increase in anxiety, depression and irritability.

\section{Health self-assessment and anxiety, depression, irritability and Ioneliness}

Negative, statistically significant correlations between health status self-assessment and the results in both scales are presented in online supplemental file 2. The selfrating of general physical and mental health decreased with increasing scores obtained by the respondents on the scale of loneliness, anxiety, depression and irritability $(p=0.000)$. The strength of the relationship was higher for mental health self-assessment $(\mathrm{R}=-0.552 ; \mathrm{R}=-0.340)$.

Table 2 Subjects' HADS-M scores $(n=890)$

\begin{tabular}{|c|c|c|c|c|c|}
\hline & & & No disorders & Borderline abnormal & Presence of disorders \\
\hline HADS-M subscales & $\mathbf{M}$ & SD & $\%$ & $\%$ & $\%$ \\
\hline Anxiety & 7.22 & 4.71 & 57 & 16 & 27 \\
\hline Depression & 5.30 & 4.29 & 68 & 18 & 14 \\
\hline Irritability & 2.47 & 1.75 & 56 & 11 & 33 \\
\hline Depression and irritability & 7.77 & 5.32 & 53 & 15 & 32 \\
\hline Total score & 15.00 & 9.56 & 58 & 17 & 25 \\
\hline
\end{tabular}

HADS-M, Modified Hospital Anxiety and Depression Scale; M, mean difference. 
Table 3 Correlations between sense of loneliness and anxiety, depression and irritability $(n=890)$

\begin{tabular}{|c|c|c|c|c|c|}
\hline \multirow[b]{2}{*}{ HADS-M subscales } & & \multicolumn{4}{|c|}{ R-UCLA subscales } \\
\hline & & Intimate others & Social others & Belonging and affiliation & Total score \\
\hline Anxiety & $\mathrm{R}$ & 0.4298 & 0.3547 & 0.3129 & 0.4597 \\
\hline \multirow[t]{2}{*}{ Depression } & $\mathrm{R}$ & 0.4324 & 0.4465 & 0.3796 & 0.5067 \\
\hline & $\mathrm{P}$ value & 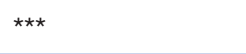 & $\star \star \star$ & 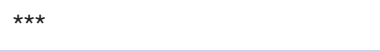 & 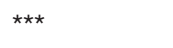 \\
\hline Depression and Irritability & $P$ value & 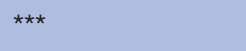 & 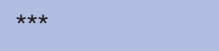 & $\star * \star$ & 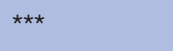 \\
\hline \multirow[t]{2}{*}{ Total score } & $\mathrm{R}$ & 0.4552 & 0.4092 & 0.3498 & 0.5018 \\
\hline & $P$ value & $\star \star \star \star ~$ & $\star \star \star$ & 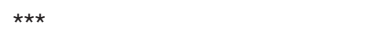 & $\star \star \star \star ~$ \\
\hline
\end{tabular}

${ }^{\star * \star} \mathrm{P}<0.001$, correlations were statistically significant.

HADS-M, Modified Hospital Anxiety and Depression Scale; R, Spearman's correlation coefficient; R-UCLA, Revised UCLA Loneliness Scale.

Respondents who reported deteriorated health compared with the pre-pandemic period also scored higher for loneliness, anxiety, depression and irritability.

\section{Sociodemographic variables and anxiety, depression and Ioneliness}

Table 4 indicates that women show significantly higher levels of anxiety, depression and irritability (16.05) compared with men (13.91). As far as the depression and loneliness subscale is concerned, the results did not differ significantly depending on gender. The analyses showed statistically significant negative correlations between R-UCLA and HADS-M scores and the age of respondents.

Younger age correlated with higher anxiety, depression and irritability, as well as higher loneliness. Correlations are presented in table 5 .

Overall, the R-UCLA scale (44.45) and the intimate others subscale (25.84) showed a significantly higher loneliness in respondents with the lowest level of education (see online supplemental file 3).

No significant correlation was found between the feeling of loneliness and the place of residence of respondents $(p=0.856)$. Anxiety, depression and irritability increased with the decreasing size of the place of residence in the total study group. This is presented in online supplemental file 4 .

The differences in the severity of loneliness, anxiety, depression and irritability depending on the professional status of respondents are reported in online supplemental file 5. Significantly, higher loneliness was shown in pupils and students for the entire R-UCLA scale (44.10), as well as the intimate others (24.72) and social others subscales (9.38).

The study showed no significant differences in the severity of anxiety, depression and irritability depending on the marital status of respondents $(p=0.322)$. Single respondents showed significantly higher loneliness (43.85) both for total and individual subscale scores (see online supplemental file 6).

Respondents living in single-family houses showed significantly higher levels of anxiety, depression and irritability on the HADS-M (15.80) and its subscales. This is presented in online supplemental file 7 .

A significant positive correlation was found between the intensity of anxiety, depression and irritability and

Table 4 HADS-M and R-UCLA scores with regard to the subjects' gender

\begin{tabular}{|c|c|c|c|c|c|c|}
\hline \multirow[b]{2}{*}{ HADS-M; R-UCLA } & \multicolumn{2}{|c|}{ Male $(n=438)$} & \multicolumn{2}{|c|}{ Female $(n=452)$} & \multirow[b]{2}{*}{$\mathbf{t}$} & \multirow[b]{2}{*}{$P$ value } \\
\hline & $\mathbf{M}$ & SD & $\mathbf{M}$ & SD & & \\
\hline Anxiety & 6.51 & 4.55 & 7.90 & 4.76 & -4.443 & $\star \star \star$ \\
\hline Depression and irritability & 7.39 & 5.26 & 8.14 & 5.36 & -2.099 & * \\
\hline HADS-M-total score & 13.91 & 9.35 & 16.05 & 9.66 & -3.351 & $\star \star \star \star ~$ \\
\hline Social others & 8.59 & 3.30 & 8.34 & 3.05 & 1.144 & \\
\hline Belonging and affiliation & 9.58 & 3.03 & 9.46 & 2.86 & 0.594 & \\
\hline R-UCLA-total score & 40.50 & 10.78 & 40.29 & 10.82 & 0.284 & \\
\hline
\end{tabular}

${ }^{*} \mathrm{P}<0.05,{ }^{* * *} \mathrm{p}<0.001$, correlations were statistically significant.

HADS-M, Modified Hospital Anxiety and Depression Scale; R-UCLA, Revised UCLA Loneliness Scale; t, Student's t-test. 
Table 5 HADS-M and R-UCLA scores with regard to the subjects' age

\begin{tabular}{|c|c|c|}
\hline & \multicolumn{2}{|l|}{ Age } \\
\hline & $\mathbf{r}$ & $P$ value \\
\hline \multicolumn{3}{|l|}{ HADS-M } \\
\hline Anxiety & -0.1580 & $\star \star \star \star ~$ \\
\hline Depression & -0.1167 & 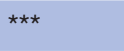 \\
\hline Depression and irritability & -0.1634 & $\star \star \star \star ~$ \\
\hline Total score & -0.1688 & 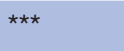 \\
\hline \multicolumn{3}{|l|}{ R-UCLA } \\
\hline Intimate others & -0.1640 & $\star \star \star *$ \\
\hline Social others & -0.1950 & \\
\hline Belonging and affiliation & -0.0977 & ** \\
\hline Total score & -0.1870 & $\star \star \star *$ \\
\hline
\end{tabular}

${ }^{\star *} \mathrm{P}<0.01$, ${ }^{\star \star *} \mathrm{p}<0.001$, correlations were statistically significant. HADS-M, Modified Hospital Anxiety and Depression Scale; r, Pearson correlation coefficient; R-UCLA, Revised UCLA Loneliness Scale.

the number of people per household (see online supplemental file 8).

The feeling of loneliness was significantly higher in the respondents living alone (see online supplemental file 9).

Correlations between the financial situation/income and loneliness, as well as the severity of anxiety, depression and irritability in the study group are shown in online supplemental file 10 . Positive, statistically significant correlations were found between these variables. The intensity of anxiety, depression and irritability increased with the deterioration of the financial situation $(\mathrm{p}=0.000)$ and lower income $(p=0.005)$. Higher loneliness was accompanied by a significantly worse financial situation $(\mathrm{p}=0.000)$ and lower income $(\mathrm{p}=0.022)$.
Variables related to the COVID-19 pandemic and anxiety, depression, irritability and loneliness

Table 6 shows the intensity of anxiety, depression and irritability as well as loneliness depending on the respondent's testing for SARS-CoV-2. Generally, a significantly higher level of anxiety, depression, irritability (23.14) and loneliness (48.42) was found in the group of patients with a positive test result.

Table 7 containing data on the respondent's experience of home quarantine shows that anxiety, depression, irritability (19.16) and loneliness (43.37) were significantly higher in those who experienced home quarantine.

Respondents who did not know any people with a positive test result scored significantly higher on the loneliness scale (40.78) (see online supplemental file 11).

Data on the correlation between respondents' knowledge of people who were/are under home quarantine or home/hospital isolation and HADS-M/R-UCLA scores are illustrated in online supplemental file 12. A significantly higher level of loneliness (41.63) was found among respondents who did not know such individuals.

Our data show that respondents who worked from home before the pandemic scored significantly higher on the individual subscales of the HADS-M and overall (19.33) on the entire scale (see online supplemental file $13)$.

People working from home during the pandemic scored higher on the anxiety subscale $(\mathrm{p}=0.041)$ and on the social others subscale $(\mathrm{p}=0.042)$ of loneliness. This is presented in online supplemental file 14 .

\section{DISCUSSION}

The aim of the study was to assess loneliness, anxiety, depression and irritability in the Polish population during the COVID-19 pandemic. The unexpected pandemic has affected the majority of the world's population, changing and complicating the everyday life of many societies.

Table 6 Diagnostic test for SARS-CoV-2 and the HADS-M and R-UCLA scores

\begin{tabular}{|c|c|c|c|c|c|c|c|c|}
\hline \multirow[b]{2}{*}{ HADS-M; R-UCLA } & \multicolumn{2}{|c|}{$\begin{array}{l}\text { No } \\
(n=780)\end{array}$} & \multicolumn{2}{|c|}{$\begin{array}{l}\text { Yes, negative result } \\
(n=74)\end{array}$} & \multicolumn{2}{|c|}{$\begin{array}{l}\text { Yes, positive result } \\
(n=14)\end{array}$} & \multirow[b]{2}{*}{$\mathbf{H}$} & \multirow[b]{2}{*}{$P$ value } \\
\hline & M & SD & $\mathbf{M}$ & SD & $M$ & SD & & \\
\hline Anxiety & 7.05 & 4.71 & 8.14 & 4.79 & 10.28 & 2.72 & 12.287 & ** \\
\hline Depression & 5.13 & 4.28 & 5.98 & 4.24 & 9.78 & 2.66 & 19.212 & 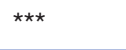 \\
\hline Depression and irritability & 7.55 & 5.30 & 8.68 & 5.53 & 12.85 & 3.43 & 16.897 & $\star \star \star ~$ \\
\hline HADS-M-total score & 14.61 & 9.55 & 16.83 & 9.91 & 23.14 & 4.62 & 16.157 & 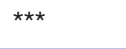 \\
\hline Intimate others & 22.30 & 6.65 & 21.74 & 7.25 & 25.85 & 7.28 & 5.797 & \\
\hline Social others & 8.40 & 3.09 & 8.58 & 3.54 & 11.35 & 4.60 & 4.268 & \\
\hline Belonging and affiliation & 9.52 & 2.90 & 9.08 & 3.06 & 11.21 & 3.94 & 4.862 & \\
\hline R-UCLA -total score & 40.23 & 10.72 & 39.40 & 11.79 & 48.42 & 10.02 & 8.762 & * \\
\hline
\end{tabular}

${ }^{*} \mathrm{P}<0.05,{ }^{* *} \mathrm{p}<0.01,{ }^{* * *} \mathrm{p}<0.001$, correlations were statistically significant.

H, Kruskal-Wallis test; HADS-M, Modified Hospital Anxiety and Depression Scale; M, mean difference; R-UCLA, Revised UCLA Loneliness Scale. 
Table 7 Home quarantine and the HADS-M and R-UCLA scores

\begin{tabular}{|c|c|c|c|c|c|c|}
\hline \multirow[b]{2}{*}{ HADS-M; R-UCLA } & \multicolumn{2}{|c|}{ No $(n=819)$} & \multicolumn{2}{|c|}{ Yes $(n=48)$} & \multirow[b]{2}{*}{$\mathbf{t}$} & \multirow{2}{*}{$\begin{array}{l}P \\
\text { value }\end{array}$} \\
\hline & $\mathbf{M}$ & SD & $\mathbf{M}$ & SD & & \\
\hline Anxiety & 7.08 & 4.67 & 8.70 & 5.26 & -2.322 & * \\
\hline Depression and irritability & 7.55 & 5.24 & 10.45 & 6.21 & -3.688 & *** \\
\hline HADS-M-total score & 14.63 & 9.43 & 19.16 & 11.11 & -3.197 & ** \\
\hline Social others & 8.42 & 3.15 & 9.33 & 3.37 & -1.937 & * \\
\hline Belonging and affiliation & 9.53 & 2.95 & 9.33 & 2.79 & 0.464 & \\
\hline R-UCLA-total score & 40.10 & 10.84 & 43.37 & 10.06 & -2.033 & * \\
\hline
\end{tabular}

${ }^{*} \mathrm{P}<0.05,{ }^{* *} \mathrm{p}<0.01,{ }^{* * *} \mathrm{p}<0.001$, correlations were statistically significant.

HADS-M, Modified Hospital Anxiety and Depression Scale; M, mean difference; R-UCLA, Revised UCLA Loneliness Scale; t, Student's t-test.

Despite certain cultural differences in social perception, it can be assumed that experiencing a pandemic is a collective, global experience, and it affects mental health regardless of the latitude, causing justified anxiety in the vast majority of humans. ${ }^{59}$ In total, the respondents had a mean R-UCLA score of $40.4 \pm 10.79$, which is lower $(42.04 \pm 11.78)$ compared with Bartoszek $e t a t^{88}$ who used the same research tool in Poland. However, it should be noted that the compared study involved mainly students $(61.6 \%)$, with a mean age of 25.5 years, who were not a representative group for Poland. A Turkish study using social networking sites, which was conducted in the general population ( $\mathrm{n}=860$, March 2020), showed a significantly higher level of loneliness $(57.94 \pm 8.26)$ compared with Poland ${ }^{60}$ Although the pandemic affects everyone, the intensity and severity of the response may vary depending on the latitude. Such comparisons between three different countries were presented by Emodi-Perlman et al. ${ }^{61}$ They found that Polish participants showed the second largest concern for mental health and relationships with relatives and friends.

Research suggests that certain demographic groups are at an increased risk of loneliness during COVID-19 selfisolation. In this study, the greatest level of loneliness was found in the age group of 16-29 years, which is consistent with the findings of Hamer and Baran ${ }^{46}$ who showed the highest level of loneliness in the youngest group (18-24 years) at each stage of the study. In the group of Turkish adolescents aged 12-18 years, the total R-UCLA score was $41.89 \pm 9.81^{62}$ and was lower compared with that obtained in this study in the group of 15-19 years old $(44.05 \pm 11.01)$. This was also confirmed in a Canadian study by Wickens $e t a l^{25}$ who found the highest scores in the group of young adults aged 18-29 years, and the lowest scores among people aged $\geq 60$ years. In our study, the growing levels of loneliness were accompanied by the younger age of the respondents, which is in line with the results of other authors, who found that during the COVID-19 pandemic, it is younger people who are more likely to suffer from loneliness, as well as the symptoms of anxiety, depression or stress. ${ }^{63-66}$ This study also found the severity of anxiety, depression and irritability to be higher in younger respondents. Research confirms that the prevalence of psychological distress in the younger population is higher than in other age groups. ${ }^{46} 67-69$ The overall average HADS-M score in the Polish population aged $\geq 60$ years was $65.18 \pm 4.06$ out of possible 80 during the second wave (October 2020) of the pandemic. ${ }^{70}$

Since the pandemic affects people's daily activities, its consequences will most probably be more severe for younger age groups than for older people (including the retired), who do not normally work and have far fewer other responsibilities outside the home. Greater loneliness perceived by younger adults may be a consequence of limited social interactions and reduced size of social networks as a result of social distancing. In comparison with the younger generations, older adults may attach more value to the quality of their interactions and social networks, rather than quantity. ${ }^{71-74}$ Furthermore, the pandemic may have affected the nature of social interaction. Limited direct personal contact with other young adults leads to greater loneliness. ${ }^{75}$ In this study, the highest levels of loneliness were found in students who had been home schooled since the first lockdown. During a pandemic, this may be due to the fact that students and adolescents, just like adults, are concerned about their future, their own health and the health of their family and friends. Isolation and limited direct social interactions both inside and outside school can increase the feeling of loneliness. ${ }^{76}$

Our study found no significant gender-related differences in the severity of loneliness, despite the fact that the data collected during the COVID-19 pandemic in other countries have shown that loneliness is more common in women than in men. ${ }^{25} 486377$ Researchers imply that this may be related to the fact that when faced with a stressor, women rely on social support and emotion-focused coping more than men and these may be compromised in a situation of limited access to family and friends during a pandemic. ${ }^{78-80}$ This may be further supported by the fact 
that women scored significantly higher for anxiety and depression than men both in this study and in the study by Hamer and Baran, ${ }^{46}$ and Babicki et al. ${ }^{49}$ McQuaid et al also report the highest rates of loneliness, depression and anxiety in young women. ${ }^{81}$

When comparing the results of this study with the one conducted in Poland by Bartoszek et $a l^{48}$ with a division into people living alone $(47.10 \pm 11.28)$ and those living with a partner or family members $(41.36 \pm 14.18)$, people living alone $(42.66 \pm 12.00)$ as well as those living with a spouse/partner $(38.68 \pm 9.45)$ and with family members $(40.55 \pm 11)$ scored lower in our study. Single people scored significantly higher compared with those living with a spouse/partner, including the intimate others subscale, which may be due to the unpleasantness of being both emotionally and physically alone. ${ }^{14}$ Wickens $e t$ $a l$ also showed a higher level of loneliness in the group of single, unmarried, widowed and divorced people. ${ }^{25}$ The analysis of potentially protective social factors showed that living with others protected against loneliness, with a $75 \%$ lower risk of the highest rate of loneliness in people living with others to those living alone. ${ }^{63}$ On the other hand, this study showed that people living with a family or with a larger number of people per household experienced significantly higher levels of anxiety, depression and irritability. On the one hand, it can be assumed that living with a family is associated with a greater possibility of receiving help and support; on the other hand, it may give rise to additional fear for the health of other family members and increase the severity of mental health problems. Furthermore, functioning in a large community in one place of residence, especially during a lockdown, may be difficult. Sharing a household with other family members, who often work or learn remotely, for a long time may lead to organisational difficulties, conflicts, and thus contribute to deteriorated mental health. ${ }^{69}$ For large families, the fear of losing a job and financial liquidity, as well as not being able to support one's own family, may intensify during a pandemic. Shahriarirad et al found a higher number of individuals per household to be a risk factor for anxiety. ${ }^{82}$

According to $\mathrm{Bu}$ et al, life in a rural community can also be a protective factor, with a $24 \%$ lower risk of the highest rate of loneliness. People with a larger circle of close friends had a $42 \%$ lower chance of experiencing the highest rate of loneliness. ${ }^{63}$ In this study, higher values on the scale and subscales of loneliness were shown in single people (43.85) compared with those in a relationship (38.72); however, no correlation between loneliness and the size of the place of residence or the number of people per household was confirmed. These data confirm previous research results implying a relationship between social network size and the perceived social support and a lower risk of loneliness. ${ }^{83-86}$ It is worth noting that the preference for face-to-face contact before the pandemic was not a risk factor for higher loneliness during lockdown, suggesting that a sudden change in social behaviour itself is not an independent predictor of loneliness. ${ }^{63}$ In this study, a larger place of residence was a protective factor for against anxiety, depression and irritability, which was not confirmed in Polish population by Babicki et al and Gambin et al. ${ }^{499}$ A study by Cao et al conducted among students showed living in urban areas as a protective factor for anxiety. ${ }^{87}$

Studies, like those by $\mathrm{Bu}$ et al, did not confirm the relationship between lower education and higher loneliness, as noted by Wickens et al or Hamer and Baran. ${ }^{25} 4663$ Lower education was a predictor of increased anxiety, depression and irritability in our study; depression in the study by Passavanti $e t a l^{758}$ and anxiety in the study by Babicki et al and Shahriarirad et al. ${ }^{49}{ }^{82}$ Respondents with lower education may lack adequate health awareness, for example, about the use of personal protective equipment, the safety of vaccinations, they may not know how to act during a crisis, distrust experts and thus show a greater fear of contracting COVID-19. This group of respondents may also experience greater fear of losing a job and a source of income. People with lower education levels may also have fewer opportunities to maintain or find employment.

Social distancing during the COVID-19 pandemic has resulted in changes in the working environment and has contributed to job insecurity. Disruptions to work can be one of the main sources of stress during the pandemic. ${ }^{89}$ A comparison of studies analysing the differences in mental health between employed and unemployed individuals during social distancing implementation has shown that the study participants who were employed had better mental health than those unemployed on all measures of mental health. ${ }^{90}$ In this study, people working from home showed the highest levels of loneliness. They scored significantly higher for the social other factor, which refers, among other things, to the perceived lack of support from one's social network and a lack of a sense of closeness with other people (in terms of their availability). People who experienced redundancy or unemployment due to the pandemic reported loneliness more often, as shown by Wickens et $a l .^{25}$ In a study by Alzueta $e t$ al, significant predictors of the severity of depression symptoms included difficulty to take care of others, and problems with transition to working from home. ${ }^{91}$ A study by Choi et $a t^{92}$ revealed higher levels of depression and anxiety in those respondents who expressed concern about not being able to work from home during the pandemic. These findings correspond with a previously established fact that employment is a protective factor for loneliness in middle-aged adults. ${ }^{93} 94$

In our study, we confirmed that people who considered their financial situation to be worse and had lower income were significantly more likely to experience loneliness, which corresponds to findings by Wickens $e t a l^{25}$ and McQuaid et al. ${ }^{81}$ Anxiety, depression and irritability increased with the decrease in income. Studies showed that respondents with low income reported anxiety and psychological stress at the early stage of the pandemic more often. ${ }^{68}$ Greater depression and anxiety symptoms 
were noted in respondents whose income was negatively impacted by social restrictions and restriction on earning opportunities. ${ }^{495}$

The occurrence and rapid spread of COVID-19 has led to a worldwide exacerbation of anxiety symptoms, which resulted in a higher incidence of severity of emotional distress. Since the outbreak of the pandemic, anxiety, symptoms of psychosis, trauma, suicidal thoughts and panic attacks have been reported in literature ${ }^{96}$ Recent research has shown that COVID-19 triggers anxiety, depression and post-traumatic stress symptoms ${ }^{65} 97$ Research in Europe assessing the consequences of quarantine showed that anxiety, depression and stress occurred in 23.8\%, $32.4 \%$ and $31.9 \%$ of the study population, respectively. ${ }^{37}$ In our study, which used the HADS-M, disorders on the anxiety subscale and the depression subscale (including irritability) were shown in $27 \%$ and $32 \%$ of respondents, respectively. A Turkish study conducted on 14-16 April 2020 using HADS showed that $23.6 \%$ and $45.1 \%$ of the population scored above the depression and anxiety cutoff point, respectively. ${ }^{98}$ Compared with our findings, the scores in the anxiety subscale were much higher, probably due to the fact that the study was conducted in the initial period of the pandemic.

Research confirms that people whose family members, relatives or friends developed COVID-19 show significantly higher severity of anxiety. ${ }^{2349} 99100$ During the outbreak of SARS-CoV-2 in Taiwan, higher levels of depression were observed among people quarantined along with their families or friends and suspected of having a SARS-CoV-2 infection. ${ }^{101}$ A COVID-19-positive patient in the family or near one's family increased state anxiety scores in adolescents. $^{62}$ Knowing a person who developed COVID-19 was a crucial factor influencing the stress and anxiety subscales. ${ }^{88}$ The reason for this may be that a family member tested positive for COVID-19 requires isolation from their family. Separation from one's family may lead to an increased risk of the development of mental disorders in young people. ${ }^{102}$ In this study, the severity of anxiety and depression was significantly higher among quarantined versus non-quarantined respondents, which corresponds with the findings by Babicki et al, Tang et al and Mazza et al. ${ }^{49} 103104$ As shown by Babicki et al, who conducted their study in November 2020, at the peak of the second wave of the pandemic in Poland, experiences with COVID-19 resulting from an illness of one's own or a family member, or death of a loved one were associated with a higher score in the GHQ. The study showed that $59.2 \%$ of the respondents met the GHQ criterion for minor mental disorders. ${ }^{49}$

This study showed positive correlations between the severity of anxiety and depression and the feeling of loneliness. Increased loneliness rates along with an increase in the severity of depression and anxiety symptoms during the pandemic were also confirmed in studies in the Canadian population. ${ }^{81}$ The relationship between loneliness and depressive symptoms was demonstrated by Killgore et al. ${ }^{9}$ A study using the three-item UCLA scale showed that more than $50 \%$ of respondents aged $\geq 60$ years complained of greater pandemic-related loneliness, which was associated with increased depression $(62 \%$ vs $9 \%$ ) and anxiety (57\% vs $9 \%) .{ }^{105}$ In a group of adolescents, a positive correlation was found between loneliness and state anxiety, and the trait anxiety. ${ }^{62}$

\section{LIMITATIONS}

Our study has several limitations. This was a crosssectional study, which may not reflect shifts in the mental state of the population over time. However, mental states change both with time and due to fluctuations in the environment around us. The research results cited in the paper were obtained at different time points during the pandemic. Therefore, there is a need to present the psychological effects of the COVID-19 pandemic over a longer and more forward-looking period of time. The results of several studies cited in the discussion section were obtained with the use of different scales assessing anxiety, depression and loneliness. The current data were collected through online surveys, which may have excluded potential respondents who lack internet access or are not knowledgeable about modern technologies. Also, 'no response' error may have occurred. However, there is evidence that online surveys have higher rates of self-disclosure on sensitive items when compared with computer-assisted telephone surveys ${ }^{106}$ and a higher data reliability, which is probably due to reduced privacy concerns. ${ }^{107}$

\section{CONCLUSIONS}

This study shows that the COVID-19 pandemic affects mental well-being of individuals as well as entire communities. It is necessary to identify those most vulnerable to loneliness, anxiety and depression during a crisis to assess health needs and proactively allocate resources during and after the pandemic. Our findings clearly demonstrated that loneliness, anxiety, depression and irritability are important factors that need to be taken into account in people tested positive for SARS-CoV-2, those under home quarantine, and those who consider their physical and mental health worse than in the pre-pandemic period. Younger age and a worse financial situation were the most important sociodemographic factors associated with higher loneliness, anxiety, depression and irritability. Loneliness was correlated with depression, anxiety and irritability scores. It is important to cater for the mental health of individuals during the COVID-19 pandemic and to promote psychological interventions to improve mental well-being in potentially vulnerable social groups.

Acknowledgements The study authors thank the participants who completed the survey.

Contributors Conception and design of the work-EK, Al and BD. Acquisition, analysis and interpretation of data for the work-EK, BK, BD and Al. Drafting the work and revising it critically for important intellectual content-EK, BD and RM. Final approval of the version to be published-EK, BK, BD, RM and Al. Agreement 
to be accountable for all aspects of the work in ensuring that questions related to the accuracy or integrity of any part of the work are appropriately investigated and resolved — EK, BK, BD, RM and Al. Guarantor - EK.

Funding The authors have not declared a specific grant for this research from any funding agency in the public, commercial or not-for-profit sectors.

Competing interests None declared.

Patient consent for publication Not required.

Ethics approval It was voluntary for the respondents to answer the questionnaire and they had the right to withdraw their undertaking of participation at any time. The study was approved by the Bioethics Committee of the Medical University of Warsaw (AKBE/232/2020). Participants gave informed consent to participate in the study before taking part.

Provenance and peer review Not commissioned; externally peer reviewed.

Data availability statement All data relevant to the study are included in the article or uploaded as supplemental information.

Supplemental material This content has been supplied by the author(s). It has not been vetted by BMJ Publishing Group Limited (BMJ) and may not have been peer-reviewed. Any opinions or recommendations discussed are solely those of the author(s) and are not endorsed by BMJ. BMJ disclaims all liability and responsibility arising from any reliance placed on the content. Where the content includes any translated material, BMJ does not warrant the accuracy and reliability of the translations (including but not limited to local regulations, clinical guidelines, terminology, drug names and drug dosages), and is not responsible for any error and/or omissions arising from translation and adaptation or otherwise.

Open access This is an open access article distributed in accordance with the Creative Commons Attribution Non Commercial (CC BY-NC 4.0) license, which permits others to distribute, remix, adapt, build upon this work non-commercially, and license their derivative works on different terms, provided the original work is properly cited, appropriate credit is given, any changes made indicated, and the use is non-commercial. See: http://creativecommons.org/licenses/by-nc/4.0/.

\section{ORCID iD}

Ewa Kobos http://orcid.org/0000-0001-7231-8411

\section{REFERENCES}

1 usnews.com. Poland reports first coronavirus case - health Minister. Available: https://www.gov.pl/web/zdrowie/pierwszy-przypadekkoronawirusa-w-polsce [Accessed 17 Dec 2020]

2 Ministry of Health (in Polish). Pierwszy przypadek koronawirusa w Polsce [First case of coronavirus in Poland]. Available: https://www. reuters.com/article/health-coronavirus-poland-idINKBN20R0X7 [Accessed 17 Dec 2020].

3 Coronavirus: what are the lockdown measures across Europe? Available: https://www.dw.com/en/coronavirus-what-are-thelockdown-measures-across-europe/a-52905137 [Accessed 17 Dec 2020].

4 Wojtyniak B, Goryński P. Health status of Polish population and its determinants 2020. Warsaw: National Institute of Public Health National Institute of Hygiene, 2020. https://www.pzh.gov.pl/

5 World Health Organization. WHO coronavirus disease (COVID-19) dashboard, 2021. Available: https://covid19.who.int/ [Accessed 27 Dec 2021].

6 Peplau LA, Perlman D. Loneliness: a sourcebook of current theory, research, and therapy. New York: Willey, 1982: 1-18.

7 Leigh-Hunt N, Bagguley D, Bash K, et al. An overview of systematic reviews on the public health consequences of social isolation and loneliness. Public Health 2017;152:157-71.

8 Cacioppo JT, Cacioppo S. The growing problem of loneliness. Lancet 2018;391:426.

9 Killgore WDS, Cloonan SA, Taylor EC, et al. Loneliness: a signature mental health concern in the era of COVID-19. Psychiatry Res 2020;290:113117.

10 Paul E, Bu F, Fancourt D. Loneliness and risk for cardiovascular disease: mechanisms and future directions. Curr Cardiol Rep 2021;23:68

11 Valtorta NK, Kanaan M, Gilbody S, et al. Loneliness, social isolation and risk of cardiovascular disease in the English longitudinal study of ageing. Eur J Prev Cardiol 2018;25:1387-96.

12 Rico-Uribe LA, Caballero FF, Martín-María N, et al. Association of loneliness with all-cause mortality: a meta-analysis. PLoS One 2018;13:e0190033.
13 Holt-Lunstad J, Smith TB, Baker M, et al. Loneliness and social isolation as risk factors for mortality: a meta-analytic review. Perspect Psychol Sci 2015;10:227-37.

14 Hawkley LC, Cacioppo JT. Loneliness matters: a theoretical and empirical review of consequences and mechanisms. Ann Behav Med 2010;40:218-27.

15 Huang Y, Zhao N. Generalized anxiety disorder, depressive symptoms and sleep quality during COVID-19 outbreak in China: a web-based cross-sectional survey. Psychiatry Res 2020;288:112954.

16 Salari N, Hosseinian-Far A, Jalali R, et al. Prevalence of stress, anxiety, depression among the general population during the COVID-19 pandemic: a systematic review and meta-analysis. Global Health 2020;16:57.

17 Tull MT, Edmonds KA, Scamaldo KM, et al. Psychological outcomes associated with Stay-at-Home orders and the perceived impact of COVID-19 on daily life. Psychiatry Res 2020;289:113098.

18 Xiang Y-T, Yang Y, Li W, et al. Timely mental health care for the 2019 novel coronavirus outbreak is urgently needed. Lancet Psychiatry 2020;7:228-9.

19 Petzold MB, Plag J, Ströhle A. Umgang MIT psychischer Belastung bei Gesundheitsfachkräften Im Rahmen Der Covid-19-Pandemie. Nervenarzt 2020;91:417-21.

20 Wu W, Zhang Y, Wang P, et al. Psychological stress of medical staffs during outbreak of COVID-19 and adjustment strategy. J Med Virol 2020;92:1962-70.

21 Lei L, Huang X, Zhang S, et al. Comparison of prevalence and associated factors of anxiety and depression among people affected by versus people unaffected by quarantine during the COVID-19 epidemic in southwestern China. Medical Science Monitor 2020;26:e924609.

22 Stieger S, Lewetz D, Swami V. Emotional well-being under conditions of Lockdown: an experience sampling study in Austria during the COVID-19 pandemic. J Happiness Stud 2021;2:1-18.

23 Groarke JM, Berry E, Graham-Wisener L, et al. Loneliness in the UK during the COVID-19 pandemic: cross-sectional results from the COVID-19 psychological wellbeing study. PLoS One 2020;15:e0239698.

24 Hoffart A, Johnson SU, Ebrahimi OV. Loneliness and social distancing during the COVID-19 pandemic: risk factors and associations with psychopathology. Front Psychiatry 2020;11:589127.

25 Wickens CM, McDonald AJ, Elton-Marshall T, et al. Loneliness in the COVID-19 pandemic: associations with age, gender and their interaction. J Psychiatr Res 2021;136:103-8.

26 Courtet $\mathrm{P}$, Olié E, Debien $\mathrm{C}$, et al. Keep socially (but not physically) connected and carry on: preventing suicide in the age of COVID-19. $J$ Clin Psychiatry 2020;81:20com13370.

27 Pitman A, Mann F, Johnson S. Advancing our understanding of loneliness and mental health problems in young people. Lancet Psychiatry 2018;5:955-6.

28 Erzen E, Cikrikci Özkan. The effect of loneliness on depression: a meta-analysis. Int J Soc Psychiatry 2018;64:427-35.

29 Martín-María N, Caballero FF, Lara E, et al. Effects of transient and chronic loneliness on major depression in older adults: a longitudinal study. Int J Geriatr Psychiatry 2021;36:76-85.

30 Cruwys T, Dingle GA, Haslam C, et al. Social group memberships protect against future depression, alleviate depression symptoms and prevent depression relapse. Soc Sci Med 2013;98:179-86.

31 Necho M, Tsehay M, Birkie M, et al. Prevalence of anxiety, depression, and psychological distress among the genera population during the COVID-19 pandemic: a systematic review and meta-analysis. Int J Soc Psychiatry 2021;67:892-906.

32 Luo M, Guo L, Yu M, et al. The psychological and mental impact of coronavirus disease 2019 (COVID-19) on medical staff and general public - A systematic review and meta-analysis. Psychiatry Res 2020;291:113190.

33 Castaldelli-Maia JM, Marziali ME, Lu Z, et al. Investigating the effect of national government physical distancing measures on depression and anxiety during the COVID-19 pandemic through meta-analysis and meta-regression. Psychol Med 2021;51:1-13.

34 Fan FC, Zhang SY, Cheng Y. Incidence of psychological illness after coronavirus outbreak: a meta-analysis study. J Epidemiol Community Health 2021;75:jech-2020-215927.

35 Bliźniewska-Kowalska KM, Halaris A, Wang S-C, et al. A review of the global impact of the COVID-19 pandemic on public mental health, with a comparison between the USA, Australia, and Poland with Taiwan and Thailand. Med Sci Monit 2021;27:e932220.

36 Kołodziejczyk A, Misiak B, Szcześniak D, et al. Coping styles, mental health, and the COVID-19 quarantine: a nationwide survey in Poland. Front Psychiatry 2021;12:625355. 
37 Brooks SK, Webster RK, Smith LE, et al. The psychological impact of quarantine and how to reduce it: rapid review of the evidence. Lancet 2020;395:912-20.

38 Yuksel D, McKee GB, Perrin PB, et al. Sleeping when the world locks down: correlates of sleep health during the COVID-19 pandemic across 59 countries. Sleep Health 2021;7:134-42.

39 Costi S, Paltrinieri S, Bressi B, et al. Poor sleep during the first peak of the SARS-CoV-2 pandemic: a cross-sectional study. Int $J$ Environ Res Public Health 2021;18:306.

40 Rubin GJ, Wessely S. The psychological effects of quarantining a City. BMJ 2020;368:m313.

41 Casagrande M, Favieri F, Tambelli R, et al. The enemy who sealed the world: effects quarantine due to the COVID-19 on sleep quality, anxiety, and psychological distress in the Italian population. Sleep Med 2020;75:12-20.

42 Panda PK, Gupta J, Chowdhury SR, et al. Psychological and behavioral impact of Lockdown and quarantine measures for COVID-19 pandemic on children, adolescents and caregivers: a systematic review and meta-analysis. $J$ Trop Pediatr 2021;67:fmaa122.

43 Li Y, Qin Q, Sun Q, et al. Insomnia and psychological reactions during the COVID-19 outbreak in China. $J$ Clin Sleep Med 2020;16:1417-8

44 Prati G, Mancini AD. The psychological impact of COVID-19 pandemic lockdowns: a review and meta-analysis of longitudinal studies and natural experiments. Psychol Med 2021;51:201-11.

45 Szczesniak D, Ciulkowicz M, Maciaszek J, et al. Psychopathological responses and face mask restrictions during the COVID-19 outbreak: results from a nationwide survey. Brain Behav Immun 2020;87:161-2.

46 Hamer K, Baran M. The influence of COVID19 pandemic on emotions, attitudes and behaviors of Poles - a summary of 10 months of the pandemic. Warsaw: Institute of Psychology at Polish Academy of Sciences, 2021: 1-20.

47 Juchnowicz D, Baj J, Forma A, et al. The outbreak of SARS-CoV-2 pandemic and the well-being of Polish students: the risk factors of the emotional distress during COVID-19 Lockdown. J Clin Med 2021;10:944.

48 Bartoszek A, Walkowiak D, Bartoszek A, et al. Mental wellbeing (depression, loneliness, insomnia, daily life fatigue) during COVID-19 related Home-Confinement-A study from Poland. Int $J$ Environ Res Public Health 2020;17:7417.

49 Babicki M, Szewczykowska I, Mastalerz-Migas A. Mental health in the era of the second wave of SARS-CoV-2: a cross-sectional study based on an online survey among online Respondents in Poland. Int J Environ Res Public Health 2021;18:2522.

50 Zhang J, $\mathrm{Lu} \mathrm{H}$, Zeng $\mathrm{H}$, et al. The differential psychological distress of populations affected by the COVID-19 pandemic. Brain Behav Immun 2020;87:49-50.

51 Holmes EA, O'Connor RC, Perry VH, et al. Multidisciplinary research priorities for the COVID-19 pandemic: a call for action for mental health science. Lancet Psychiatry 2020;7:547-60.

52 ICC/ESOMAR (the world association for social, opinion and market research) International Code on market, opinion and social research. Available: http://www.ofbor.pl > public > File > Miedzynaro [Accessed 18 Dec 2021].

53 Kwiatkowska M, Rogoza R, Kwiatkowska K. Analysis of the psychometric properties of the revised UCLA loneliness scale in a Polish adolescent sample. Current Issues in Personality Psychology 2018;6:164-70.

54 Russell D, Peplau LA, Cutrona CE. The revised UCLA loneliness scale: concurrent and discriminant validity evidence. J Pers Soc Psychol 1980;39:472-80.

55 Austin BA. Factorial structure of the UCLA loneliness scale. Psychol Rep 1983;53:883-9.

56 Perry GR. Loneliness and coping among tertiary-level adult cancer patients in the home. Cancer Nurs 1990;13:293-302.

57 Majkowicz M. Practical assessment of palliative care efficacy: selected research techniques. In: de Walden-Gałuszko K, Majkowicz M, eds. Evaluation of palliative care quality in theory and practice. Gdańsk, DC: Medical Academy, 2000: 26-31.

58 Zigmond AS, Snaith RP. The hospital anxiety and depression scale. Acta Psychiatr Scand 1983;67:361-70.

59 Sokół-Szałowka M. Mental health impact of quarantine during the COVID-19 pandemic. Psychiatry 2021;18:57-62.

60 Yıldııım M, Kızılgeçit M, Seçer İsmail, et al. Meaning in Life, Religious Coping, and Loneliness During the Coronavirus Health Crisis in Turkey. J Relig Health 2021;60:2371-85.

61 Emodi-Perlman A, Eli I, Uziel N, et al. Public concerns during the COVID-19 Lockdown: a multicultural cross-sectional study among Internet survey Respondents in three countries. J Clin Med 2021:10:1577.
62 Kılınçel Şenay, Kılınçel O, Muratdağı G, et al. Factors affecting the anxiety levels of adolescents in home-quarantine during COVID-19 pandemic in turkey. Asia Pac Psychiatry 2021;13:e12406.

63 Bu F, Steptoe A, Fancourt D. Loneliness during a strict lockdown: trajectories and predictors during the COVID-19 pandemic in 38,217 United Kingdom adults. Soc Sci Med 2020;265:113521.

64 Losada-Baltar A, Martínez-Huertas José Ángel, Jiménez-Gonzalo $\mathrm{L}$, et al. Longitudinal correlates of loneliness and psychological distress during the lockdown situation due to COVID-19. Effects of age and self-perceptions of aging. J Gerontol B Psychol Sci Soc Sci 2021:gbab012.

65 Ahmed MZ, Ahmed O, Aibao Z, et al. Epidemic of COVID-19 in China and associated psychological problems. Asian J Psychiatr 2020;51:102092.

66 Qiu J, Shen B, Zhao M, et al. A nationwide survey of psychological distress among Chinese people in the COVID-19 epidemic: implications and policy recommendations. Gen Psychiatr 2020;33:e100213.

67 Shanahan L, Steinhoff A, Bechtiger L, et al. Emotional distress in young adults during the COVID-19 pandemic: evidence of risk and resilience from a longitudinal cohort study. Psychol Med 2020:1-10.

68 Nagasu M, Muto K, Yamamoto I. Impacts of anxiety and socioeconomic factors on mental health in the early phases of the COVID-19 pandemic in the general population in Japan: a webbased survey. PLoS One 2021;16:e0247705.

69 Gambin M, Sękowski M, Woźniak-Prus M, et al. Generalized anxiety and depressive symptoms in various age groups during the COVID-19 lockdown in Poland. specific predictors and differences in symptoms severity. Compr Psychiatry 2021;105:152222.

70 Dziedzic B, Idzik A, Kobos E, et al. Loneliness and mental health among the elderly in Poland during the COVID-19 pandemic. BMC Public Health 2021;21:1976.

71 Victor CR, Yang K. The prevalence of loneliness among adults: a case study of the United Kingdom. J Psychol 2012;146:85-104.

72 Carmichael CL, Reis HT, Duberstein PR. In your 20S it's quantity, in your $30 S$ it's quality: the prognostic value of social activity across 30 years of adulthood. Psychol Aging 2015;30:95-105.

73 Luhmann M, Hawkley LC. Age differences in loneliness from late adolescence to oldest old age. Dev Psychol 2016;52:943-59.

74 Nicolaisen $\mathrm{M}$, Thorsen $\mathrm{K}$. What are friends for? friendships and loneliness over the Lifespan-From 18 to 79 years. Int J Aging Hum Dev 2017;84:126-58.

75 Child ST, Lawton L. Loneliness and social isolation among young and late middle-age adults: associations with personal networks and social participation. Aging Ment Health 2019;23:196-204.

76 Elmer T, Mepham K, Stadtfeld C. Students under lockdown: comparisons of students' social networks and mental health before and during the COVID-19 crisis in Switzerland. PLoS One 2020;15:e0236337.

77 Losada-Baltar A, Jiménez-Gonzalo L, Gallego-Alberto L, et al. "We Are Staying at Home." Association of Self-perceptions of Aging, Personal and Family Resources, and Loneliness With Psychological Distress During the Lock-Down Period of COVID-19. J Gerontol B Psychol Sci Soc Sci 2021;76:e10-16.

78 Matud MP. Gender differences in stress and coping styles. Personality and Individual Differences 2004:37:1401-15.

79 Matud MP, Bethencourt JM, Ibáñez I. Gender differences in psychological distress in Spain. Int J Soc Psychiatry 2015;61:560-8.

80 Ptacek JT, Smith RE, Dodge KL. Gender differences in coping with stress: when stressor and appraisals do not differ. Personality and Social Psychology Bulletin 1994;20:421-30.

81 McQuaid RJ, Cox SML, Ogunlana A, et al. The burden of loneliness: implications of the social determinants of health during COVID-19. Psychiatry Res 2021;296:113648.

82 Shahriarirad R, Erfani A, Ranjbar K, et al. The mental health impact of COVID-19 outbreak: a nationwide survey in Iran. Int J Ment Health Syst 2021;15:19.

83 Kemperman A, van den Berg P, Weijs-Perrée M, et al. Loneliness of older adults: social network and the living environment. Int $J$ Environ Res Public Health 2019;16:406.

84 Jaspal R, Breakwell GM. Socio-Economic inequalities in social network, loneliness and mental health during the COVID-19 pandemic. Int J Soc Psychiatry 2020:20764020976694.

85 Tomaz SA, Coffee P, Ryde GC, et al. Loneliness, wellbeing, and social activity in Scottish older adults resulting from social distancing during the COVID-19 pandemic. Int J Environ Res Public Health 2021:18:4517.

86 Lee C-YS, Goldstein SE. Loneliness, stress, and social support in young adulthood: does the source of support matter? $J$ Youth Adolesc 2016;45:568-80. 
87 Cao W, Fang Z, Hou G, et al. The psychological impact of the COVID-19 epidemic on college students in China. Psychiatry Res 2020;287:112934.

88 Passavanti M, Argentieri A, Barbieri DM, et al. The psychological impact of COVID-19 and restrictive measures in the world. J Affect Disord 2021;283:36-51.

89 Zheng J, Morstead T, Sin N, et al. Psychological distress in North America during COVID-19: the role of pandemic-related stressors. Soc Sci Med 2021;270:113687.

90 Geirdal Amy Østertun, Ruffolo M, Leung J, et al. Mental health, quality of life, wellbeing, loneliness and use of social media in a time of social distancing during the COVID-19 outbreak. A cross-country comparative study. J Ment Health 2021;30:148-55.

91 Alzueta E, Perrin P, Baker FC, et al. How the COVID-19 pandemic has changed our lives: a study of psychological correlates across 59 countries. J Clin Psychol 2021;77:556-70.

92 Choi EPH, Hui BPH, Wan EYF. Depression and anxiety in Hong Kong during COVID-19. Int J Environ Res Public Health 2020;17:3740.

93 Franssen T, Stijnen M, Hamers F, et al. Age differences in demographic, social and health-related factors associated with loneliness across the adult life span (19-65 years): a cross-sectional study in the Netherlands. BMC Public Health 2020;20:1118.

94 Matthews T, Danese A, Caspi A, et al. Lonely young adults in modern Britain: findings from an epidemiological cohort study. Psychol Med 2019;49:268-77.

95 Feter N, Caputo EL, Doring IR, et al. Sharp increase in depression and anxiety among Brazilian adults during the COVID-19 pandemic: findings from the PAMPA cohort. Public Health 2021;190:101-7.

96 World Health Organization. Mental health and psychosocial considerations during the COVID-19 outbreak, 18 March 2020. World Health organization, 2020. Available: https://apps.who.int/iris/ handle/10665/331490 [Accessed 09 Aug 2021].

97 Zhou S-J, Zhang L-G, Wang L-L, et al. Prevalence and sociodemographic correlates of psychological health problems in
Chinese adolescents during the outbreak of COVID-19. Eur Child Adolesc Psychiatry 2020;29:749-58.

98 Özdin S, Bayrak Özdin Şükriye. Levels and predictors of anxiety, depression and health anxiety during COVID-19 pandemic in Turkish Society: the importance of gender. Int J Soc Psychiatry 2020;66:504-11.

99 Moghanibashi-Mansourieh A. Assessing the anxiety level of Iranian general population during COVID-19 outbreak. Asian J Psychiatr 2020;51:102076.

100 Wang C, Pan R, Wan X, et al. Immediate psychological responses and associated factors during the initial stage of the 2019 coronavirus disease (COVID-19) epidemic among the general population in China. Int J Environ Res Public Health 2020;17:1729.

101 Ko C-H, Yen C-F, Yen J-Y, et al. Psychosocial impact among the public of the severe acute respiratory syndrome epidemic in Taiwan. Psychiatry Clin Neurosci 2006;60:397-403.

102 Golberstein E, Wen H, Miller BF. Coronavirus disease 2019 (COVID-19) and mental health for children and adolescents. JAMA Pediatr 2020;174:819-20.

103 Tang F, Liang J, Zhang $\mathrm{H}$, et al. COVID-19 related depression and anxiety among quarantined respondents. Psychol Health 2021;36:164-78.

104 Mazza C, Ricci E, Biondi S, et al. A nationwide survey of psychological distress among Italian people during the COVID-19 pandemic: immediate psychological responses and associated factors. Int J Environ Res Public Health 2020;17:3165.

105 Kotwal AA, Holt-Lunstad J, Newmark RL, et al. Social isolation and loneliness among San Francisco Bay area older adults during the COVID-19 Shelter-in-Place orders. J Am Geriatr Soc 2021;69:20-9.

106 Milton AC, Ellis LA, Davenport TA, et al. Comparison of selfreported telephone interviewing and web-based survey responses: findings from the second Australian young and well national survey. JMIR Ment Health 2017;4:e37.

107 Braunsberger K, Wybenga H, Gates R. A comparison of reliability between telephone and web-based surveys. Journal of Business Research 2007;60:758-64 